\title{
Periodic Climate Change on Mars: Review of Evidence and Effects on Distribution of Volatiles ${ }^{1}$
}

\author{
MICHAEL H. CARR \\ U.S. Geological Survey, 345 Middlefield Road, Menlo Park, California 94025
}

Received November 9, 1981; revised December 14, 1981

\begin{abstract}
The polar regions of Mars preserve, in both their layering and their topography, a record of recent climate changes. Because of the coincidence of the growth of the northern seasonal cap with global dust storms, dust may be currently accumulating on the northern cap, but conditions at the poles will alternate with the precessional cycle. Deposition is also modulated by changes in eccentricity and obliquity, which interact complexly, affecting initiation of global dust storms, the stability of volatiles at the surface, and global wind regimes. Formation of spiral valleys and low undulations on the surface of the layered deposits may result from preferential sublimation of volatiles on sunward-facing slopes and condensation on the adjacent flats, with the rates also modulated by astronomically caused insolation variations. Lack of impact craters on the surface and lack of interruption of the layers by impact scars suggest that the polar deposits are no more than a few million years old. Older deposits may have been periodically removed, as indicated by etch-pitted terrain at the south pole and by superposition relations around the periphery of the present layered deposits. Evidence of ancient periodic climate changes that occurred before formation of the present layered terrain is fragmentary but includes pedestal craters, parallel moraine-like ridges, and etched ground at high latitudes. Perturbation of the orbital motions also results in adsorption and desorption of volatiles in the regolith, which leads to variations in atmospheric pressure and partial dehydration of the equatorial near-surface materials.
\end{abstract}

\section{INTRODUCTION}

The polar regions retain the best geologic evidence for periodic climate changes on Mars. At each pole is a thick sequence of layered deposits and while their exact nature is not known, they probably consist largely of eolian debris cemented by volatiles. Their rate of sedimentation should, therefore, vary as wind regimes and volatile stabilities change in response to global climate changes and a record of the changes should be preserved in the layering. Climate changes may also be recorded in the topography of the deposits. On their surface are numerous low escarpments and valleys that have a regular spacing as though they were caused by periodic events. In addition, deep valleys are incised into the deposits, indicating that erosion as

'Presented at the "Workshop on Quasi-Periodic Climatic Changes on Earth and Mars" held at NASA's Ames Research center, Moffett Field, California, February $24-26,1981$. well as deposition has taken place at the poles, which suggests again that climate changes may have occurred. The almost complete lack of impact craters on the layered deposits suggests that they are no more than a few million years old, so that the changes that they record are in the relatively recent geologic past. Surrounding the polar deposits, however, are much older surfaces. These also give indications of climate changes, although here the record is far more fragmentary and even more difficult to interpret.

The purpose of this paper is to review briefly our current knowledge of the geology of the polar regions and to examine how periodic climate changes might have affected geologic processes there. Different theories for the formation of the layered terrain and its peculiar topography are examined, as is the present depositional regime. The stability of volatiles in the polar region is discussed with particular emphasis on how the precessional cycle and 
changes in eccentricity and obliquity might cause interchange between the atmosphere and the surface. The review is brief. For a more thorough and quantitative treatment see Toon et al. (1980).

\section{LAYERED TERRAIN}

The layered deposits occur at both poles and cover most of the area poleward of the $80^{\circ}$ latitude circle. They are easily recognizable since they form a smooth, crater-free surface that contrasts markedly with the generally more textured cratered topography of the surrounding areas. During summer the layered deposits in the south are largely frost free because of the small size of the southern remnant cap. In the north, however, the remnant summer cap is more extensive, and the deposits retain a discontinuous frost cover even in the middle of summer. Parts of the outer boundary of the deposits are sharp, consisting of an outward-facing, slightly convex upward, escarpment; other parts of the boundary have a feather edge. Interrupting the smooth upper surface are numerous valleys and low escarpments which mostly curl out from the pole in a counterclockwise (eastward) direction in the north and in a predominantly clockwise (westward) direction in the south. At both poles some large valleys also cut across the general trends. Preferential removal of frost on the equatorwardfacing slopes within the layered terrain gives the poles a characteristic swirl texture in summer. Between the linear valleys and escarpments the terrain is mostly flat and featureless, although some low undulations have been detected that are parallel to the larger topographic features (Cutts et al., 1979). The valleys and escarpments are approximately equally spaced, being about 50 $\mathrm{km}$ apart; the minor undulations are close to $10 \mathrm{~km}$ apart. Valley and escarpment relief ranges from 100 to $1000 \mathrm{~m}$ and slopes range as high as $6^{\circ}$ (Dzurisin and Blasius, 1975). The total thickness of the deposits has been estimated at $1-2 \mathrm{~km}$ in the south and $4-6 \mathrm{~km}$ in the north (Dzurisin and Blasius, 1975).

The layering is best seen on defrosted slopes where albedo differences between individual layers cause a fine horizontal banding. Terraces are also visible in places, particularly in the south, since larger areas become defrosted in summer. Layer thicknesses of 10 to $50 \mathrm{~m}$ have been measured (Dzurisin and Blasius, 1975) but the layering almost certainly continues down below the limiting resolution of the available photography. Individual layers can commonly be traced for hundreds of kilometers (Cutts, 1973; Murray et al., 1972). Unconformities are present but rare. Disruption of the layering such as might be expected from impacts is also rare, suggesting that the small number of superimposed craters is truly indicative of a young age and is not due to some self-annealing process or infilling.

\section{CLIMATIC VARIATIONS AS A CAUSE OF THE LAYERING}

The layered deposits are believed to be accumulations of volatiles and dust with both the relative and absolute accumulation rate of each component being somehow modulated by climatic variations (Murray et al., 1972; Cutts, 1973; Cutts et al., 1976; Sharp, 1974). The summer remnant caps provide clues as to how the modulation might be effected. The two residual caps differ from one another in part as a result of hemispheric asymmetries caused by global dust storms. The northern remnant cap is almost certainly water-ice. Brightness temperatures over most of the cap during late 1976, when it was summer in the north, were near $205^{\circ} \mathrm{K}$, close to the frost point of water in a well-mixed atmosphere containing only a few tens of precipitable (pr) micrometers of water (Kieffer et al., 1976). In addition, relatively large amounts of water vapor $(80-100 \mathrm{pr} \mu \mathrm{m})$ were in the atmosphere over the poles (Farmer et al., 1976), indicating that the atmosphere was close to saturation. Half a Martian year later, during 
southern summer, similar measurements were made over the southern cap. The temperatures there showed a marked spectral contrast, but measured at $20 \mu \mathrm{m}$ they were between 150 and $160^{\circ} \mathrm{K}$, just above the frost point for $\mathrm{CO}_{2}$ and substantially lower than those of the northern cap at the same season. In addition, no significant increase in water vapor was detected over the pole; the level was the same as elsewhere on the planet at this season (6 pr $\mu \mathrm{m}$ ) (Farmer and Doms, 1979). The lack of water at the surface does not, however, imply that waterice is absent; it merely reflects the low rate of sublimation at the measured temperatures.

Kieffer and Palluconi (1979) interpret the south pole temperatures as caused mainly by $\mathrm{CO}_{2}$ at its frost point $\left(148^{\circ} \mathrm{K}\right)$ but with warmer defrosted areas within the field of view of their detectors, resulting in integrated temperatures slightly above the frost point. They concluded that the remnant southern cap is almost completely covered by $\mathrm{CO}_{2}$ frost and ascribed the differences between the caps to the effects of global dust storms. The dust storms start in the southern hemisphere close to perihelion raising into the atmosphere large amounts of dust which cause its optical depth to increase from values close to 1 to values between 5 and 10 (Pollack et al., 1979). The remnant southern cap is thus partly shielded from the Sun in summer. At the same time, $\mathrm{CO}_{2}$ is condensing out at the northern winter pole in a dusty atmosphere. The $\mathrm{CO}_{2}$ probably nucleates around the dust grains and formation of the northern seasonal cap may play a significant role in scavenging dust from the atmosphere. In contrast, in the opposite season, when the south polar cap is forming, the atmosphere is clear so little dust is incorporated into the seasonal cap. The south pole, therefore, has clean high-albedo ice partly shielded from the summer Sun, whereas the north has dirty ice over which the atmosphere is clear in summer. The results are warmer temperatures on the remnant northern cap than on the remnant southern cap, complete volatilization of $\mathrm{CO}_{2}$ at the north pole during northern summer, and retention of a small remnant $\mathrm{CO}_{2}$ cap in the south during southern summer. Whether or not water is present in the remnant southern cap is still uncertain, for the cold southern temperatures prevent its detection. It appears probable, however, that the southern cap acts as a trap for water since, once in it, the water cannot get out because the temperatures never reach the frost point, at least under present climatic conditions. The behavior of the caps may alternate with the $51,000-$ year precessional cycle. In 25,000 years dust storms may occur during northern summers and the south polar cap may be the one that is warm and dirty as dust is preferentially deposited there.

Orbital motions other than precession may also affect accumulation of dust and ice. The eccentricity of the Mars orbit is currently 0.093 but it oscillates between 0.01 and 0.14 with characteristic periods of 95,000 and $2 \times 10^{6}$ years (Murray et al., 1973). Clearly, when the orbit is nearly circular the effects of the precessional cycle are minimized, since hemispheric differences are minimized. In contrast, at the maximum eccentricity the precessional effects are amplified and differences between the two hemispheres become extreme. Thus, in periods of high eccentricity deposition rates at the poles should alternate on a 51,000-year cycle whereas during periods of low eccentricity any deposition should be relatively uniform.

An additional complication is caused by global dust storms. At present the threshold conditions for initiation are reached only during southern summer. During periods of low eccentricity, when both hemispheres have similar climatic regimes, the threshold conditions may not be achieved in either hemisphere so a gap may occur in the depositional record.

Conditions at the poles are also affected 
by the planet's obliquity, the angle between the equatorial plane and the plane of the orbit. The obliquity ranges between 11 and $38^{\circ}$ (Ward et al., 1979), oscillating at a period of $1.2 \times 10^{5}$ years with an amplitude that varies with a period of $1.2 \times 10^{6}$ years. The present obliquity is $25^{\circ}$, close to the midpoint of the full range. At high obliquities summer temperatures in the polar regions will tend to be higher, thereby causing desorption of near-surface polar volatiles and a shrinking of the remnant caps. At the same time equatorial temperatures will fall, promoting adsorption in the regolith there. Conversely, periods of low obliquity will be characterized by relatively low peak summer temperatures at high latitudes. The rate of formation and stability of any ice-cemented deposits at the poles will, therefore, be affected by obliquity changes.

\section{DEPOSITIONAL RATES}

Pollack et al. (1979) calculated the present rate of dust deposition in the polar regions on the basis of the amount of dust observed in the atmosphere during the 1977 dust storm. The amount of dust added to the atmosphere that year was equivalent to increasing the optical depth by a factor of 7.5 , which is equivalent to $4 \times 10^{-3} \mathrm{~g} / \mathrm{cm}^{2}$. Assuming half the dust falls in the $6 \%$ of the planet that is north of $60^{\circ} \mathrm{N}$, and that the final deposit is half water-ice with a $50 \%$ porosity, Pollack et al. estimated a sedimentation rate of $4 \times 10^{-2} \mathrm{~cm} /$ year, at which rate it would take about $10^{5}$ years to deposit a 30-m-thick layer. To deposit 2 to 3 $\mathrm{km}$ would take 6-10 million years.

Cutts (1980) pointed out that the sequence of events may be far more complicated than that just outlined in that long gaps may occur between periods of sedimentation. The present rates depend largely on dust raised into the atmosphere by the dust storms. The initiation of global storms depends on both eccentricity and obliquity. These interrelate complexly in that they vary with different periods. The sedimentary record may contain gaps which represent periods when conditions were such that dust storms did not occur. Similarly, the condensation and stability of volatiles depend on obliquity, eccentricity, and precession in a complex manner not fully understood. We can conclude however that at the present rate the observed deposits could accumulate in a relatively short time, a few tens of millions of years at the most, which is consistent with the young ages implied by the lack of superimposed impact craters.

The relatively young age is one of the more puzzling aspects of the layered terrain. Cutts et al. (1976) note that in an area of $8 \times 10^{5} \mathrm{~km}^{2}$ of layered terrain in the north, not one crater as large as $300 \mathrm{~m}$ was observed. If this lack of craters was due solely to age it would imply a surface less than 1 my old. Possibly some annealing and infilling of small craters do occur despite the lack of obvious interruption by impact scars. Even with this concession, however, ages much in excess of a few tens of millions of years are unlikely. What then was occurring at the poles previous to the last few million years? Either the conditions were much like they are at present and the old layered terrain has been removed, or the present era is unique. The latter possibility is unlikely for it would require us to be coincidentally observing the planet shortly after the layered deposits first started to accumulate. Some clues as to how the older layered sequences might have been erased may be provided by the present topography of the layered terrain.

\section{ORIGIN OF THE TOPOGRAPHY OF THE LAYERED DEPOSITS}

While there is general agreement that the layered sequences at the pole originate by 
deposition of volatiles and wind-blown dust modulated by climatic variations, no such concensus has been achieved on the origin of the valleys and scarps that form the distinctive swirl texture of the deposits. A question of some interest is whether the relief is forming contemporaneously with the deposits or whether periods of deposition alternate with periods of erosion during which the valleys and escarpments form. In the first case, climatic variations comparable to those that cause variations in sedimentation rates are implied; in the second case, larger climatic variations are needed, with depositional and erosional periods alternating on time scales that are long compared with those represented by the layers in the sediments.

Probable mechanisms for creating the relief are wind erosion and differential sublimation and condensation. Evidence for wind erosion at the poles is widespread. Cutts (1973) gives several examples of a fine linear fluting on the surface of the layered deposits which he plausibly interprets as caused by the wind. In addition, adjacent to the main body of layered deposits at the south pole are some etched and pitted terrains (Sharp, 1973). In these areas the surface is generally smooth except for numerous irregularly shaped, steep-sided pits and a fine fluting on the surface. Both Cutts (1973) and Sharp (1973) consider wind as the most likely agent for forming the fluting and removing the surface material to form the pits, although sublimation of volatiles or basal melting of volatiles (Howard, 1982) could also have been involved. No comparable pitted terrain occurs in the north.

Differential sublimation and condensation may also have played a role in creating the present topography. Howard (1978) suggested that the layered terrain is composed of ice and dust and is in a state of dynamic equilibrium with present climatic conditions. According to his hypothesis, erosion and deposition are occurring simul- taneously with both the relief and the layering caused by the same climatic variations. He proposed that ice sublimes on sunwardfacing slopes causing the layered materials to disaggregate. The dust released is then readily mobilized by the wind and becomes cemented onto the adjacent flats where volatiles driven off from the dark slopes refreeze. The sequence exposed on the escarpment slopes is thus eroded away and new deposits are built up on the adjacent flats. He demonstrated by computer modeling that this process will cause minor variations in slopes to become accentuated and ultimately consolidated into discrete linear escarpments separated by broad smooth areas. In effect, a growing escarpment eats into the higher ground, eliminating local slope variations and leaving behind a smoothed-off surface on the ground over which the escarpment has advanced. The curling spiral pattern, he suggests, is caused by a slight preferential erosion on westward-, as opposed to eastward-, facing scarps because afternoon temperatures are higher than morning temperatures as a result of a slight atmospheric warming during the day. Howard thus envisages a terrain which is constantly being renewed, as the escarpments slowly march across the landscape. The young age of the terrain is merely a measure of the rate at which erosion is taking place and the whole sequence is being reformed.

Cutts et al. (1979) also invoked preferential ablation to explain the topography of the layered deposits. They suggested that dust accumulates at the poles only in the areas covered by the perennial cap. In areas outside the perennial cap, any dust which has accumulated during the year is removed when the seasonal cap dissipates in spring. They noted that most of the linear features that are defrosted in summer are valleys and not escarpments as formerly thought, and second, that the intervening flats have slight undulations that follow the 
general trend of the valleys. They suggested that the minor undulations mark positions of the former edge of the perennial cap and hence a former boundary of accumulation of the layered terrain. The undulations are muted because later layers drape over the former edges as the region of deposition increases in size. The differing extent of the layered terrain, as indicated by the undulations, he ascribed to climate changes. They further postulated that the spiral valleys form in a manner analogous to the escarpments in Howard's hypothesis. Slopes on some of the undulations exceed those required to retain frost in summer so materials deposited on these slopes in winter are removed when the ice sublimes in summer. In contrast, dust and ice are retained on the adjacent, flatter ground. As a result linear zones of nondeposition cut across the layered terrain following the former positions of the outer margin of dust accumulation. Over an extended period of time these linear zones will develop into valleys as material accumulates on the adjacent flat areas. Only every third or fourth undulation is steep enough to be defrosted and Cutts et al. speculated that some periodic modulation in amplitude of the undulations could have been caused by periodic climatic variations of astronomic origin. In the Cutts et al. hypothesis, therefore, the spiral pattern is static, and follows former positions of the edge of the perennial ice; in the Howard hypothesis the pattern is dynamic and the terrain is constantly being renewed.

The Howard and Cutts et al. hypotheses do not exhaust the possibilities. The presence of secondary craters on the layered deposits coupled with their absence on adjacent areas where the layered deposits are missing suggests erosion around the periphery of the deposits (Carr, 1981). Extensive erosion of the layered deposits is also implied by the etched and pitted terrains (Sharp, 1973) if they are eroded remnants of layered deposits. In addition, huge valleys
(Chasma Australe and Chasma Borealis) in the sequences at both poles suggest amounts of erosion that are difficult to explain by either the Howard or Cutts et al. hypotheses. Other erosional mechanisms appear to be needed. Erosion and deposition could be occurring penecontemporaneously, alternating on relatively short time scales such as with the seasons or the precessional cycle. This almost certainly occurs. Albedo differences caused by the layers are visible on defrosted ground even in the north where active deposition is taking place. Their visibility indicates that the dark bands are being kept clean of dust, probably by the wind. The question is not whether erosion is taking place but the scale and rate at which it is occurring.

Of particular interest is whether the large valleys, the apparent retreat of the edge of the layered terrain in the south, and the lack of old layered terrain can all be explained on the basis of the present conditions or whether larger, longer-term, climatic changes are required. At present Mars is in the midpoint of its obliquity range. At the maximum value of $38^{\circ}$ the amount of insolation falling on the poles is $35 \%$ higher than at present. If the layered terrain is cemented by water-ice, then the increased insolation could result in increased sublimation, which would cause disaggregation, thereby facilitating erosion. Erosion would occur preferentially on sunward-facing slopes around the periphery of the deposits. Removal of the polar layered deposits every 600,000 years following the $1.2 \times 10^{6}$-year amplitude variations in the obliquity is, however, unlikely, for accumulation of the deposits between erasures would require depositional rates of 0.5 $\mathrm{cm} /$ year, which are excessively high. If the layered deposits are periodically removed, their removal must be on a time scale of at least millions of years. Perhaps a combination of high obliquity and high eccentricity is required and the combination occurs only once every several million years. 
While most of the evidence for periodic climate changes concerns the relatively recent geologic past, several lines of evidence suggest that periodic changes also occurred in the more distant past. Soderblom et al. (1973) suggested that many of the features of the plains in the northern high latitudes can be explained by repeated deposition and erosion of debris blankets, which would require periodic climate changes. This model is supported by the etched and pitted appearance of much of the terrain at high latitudes, as revealed in Viking highresolution images (Carr, 1981). Further evidence of periodic changes are arrays of parallel ridges which have been likened to terminal glacial moraines and ascribed to formation during episodic removal of former debris blankets (Carr and Schaber, 1977) or ice sheets (Lucchitta, 1981).

\section{NEAR-SURFACE STORAGE OF CARBON DIOXIDE}

Fanale and Cannon (1974, 1979) and Fanale (1976) have pointed to the importance of the regolith as a sink for volatiles, especially carbon dioxide and water, and have shown that climate changes can cause interchange of carbon dioxide between the surface and the atmosphere, thereby changing the atmospheric pressure which could have further climatic effects. Several lines of evidence indicate that the present atmosphere represents only a fraction of the volatiles that have outgassed from the planet (McElroy et al., 1977; Pollack and Black, 1979). Particularly significant is the lack of any observable fractionation of the oxygen isotopes in the Martian atmosphere despite a substantial enrichment in ${ }^{15} \mathrm{~N}$ and several plausible mechanisms for exospheric loss of oxygen which would cause the remaining oxygen to be enriched in the heavy isotope. The most straightforward explanation of the lack of detectable enrichment is that the oxygen presently in the atmosphere constitutes only a small fraction of that which is subject to isotopic modification by exospheric processes. The rest exists in ground, close to the surface, where it can interact dynamically with the atmosphere and so dilute the fractionation effects. The most plausible form is $\mathrm{CO}_{2}$ or $\mathrm{H}_{2} \mathrm{O}$ which could be added to or driven from the surface materials as climatic conditions change. The exchange cannot be restricted to some more clement period in the planet's distant past; it must be either continuous or recent, otherwise some fractionation would be detected.

The storage capacity of the regolith for volatiles depends on its thickness and structure and may be quite different for water and carbon dioxide in that much of the carbon dioxide may be adsorbed while much of the water may be interstitial or chemically bound. As applied to the Moon, the term regolith normally refers to a layer of fine-grained, largely impact-generated, fragmental debris close to the surface. The thickest regolith was produced early in the planet's history when impact rates were highest. The lunar regolith is, for example, estimated to be tens of meters thick in the lunar highlands, but only meters thick on the mare. Beneath the lunar highlands' regolith, however, is a much thicker megaregolith of rubble and fractured rock and this must also be present on the Martian cratered terrain. On the Martian highlands there is probably a continuous transition from a fine-grained soil at the surface, to coarse fragmental debris at slightly greater depths, then fractured rocks roughly in place, finally to largely undeformed rocks below. The brecciated zone is probably porous and its thickness limited by annealing and closure of pore spaces at depth as a result of self-compression and volcanic processes. On the Moon, seismic evidence (Latham et al., 1971) suggests that the surface materials retain some porosity to depths as large as $25 \mathrm{~km}$. The depth for Mars is almost certainly shallower $(10 \mathrm{~km})$ because of higher gravity and higher heat 
flow (Carr, 1979). The unconsolidated rubble is probably considerably thinner than the brecciated zone but thicknesses of 1$1.5 \mathrm{~km}$ are plausible (Fanale and Cannon, 1974). The simple picture just outlined is locally complicated by deposits which postdate the early high-impact flux. Such deposits will develop their own impact regolith, but this is likely to be thin, less than that on the lunar maria, because of the protective effects of the atmosphere. The old thick megaregolith must, however, exist at depths below the younger deposits, except in those, probably rare cases, such as beneath volcanoes, where the megaregolith may have been destroyed by metamorphism.

Eolian debris is, however, more likely to be a significant sink for volatiles than an impact-generated regolith or megaregolith. Soderblom et al. (1973) suggested that large parts of the equatorial region are swept free of fine-grained materials, whereas the high latitudes appear to be regions of accumulation. This model is substantiated by highresolution pictures which show that most of the terrain between the $40^{\circ}$ latitude circle and the polar layered deposits has a scabby appearance rarely seen at lower latitudes (Carr, 1981). It appears as though the terrain was partly covered by extensively eroded, thin deposits. Analyses by the Viking landers suggest that the mobile finegrained debris on the Martian surface has been homogenized over the whole planet, probably as a result of global dust storms. It is reasonable, therefore, to conclude that these eroded debris blankets at mid to high latitudes are similar to the materials analyzed at the Viking sites; that is, they consist largely of weathered debris and may contain a significant fraction of montmorillonitic clays (Toulmin et al., 1977).

Fanale and Cannon (1979) showed that montmorillonite clays have a substantial adsorptive capacity for $\mathrm{CO}_{2}$ and that the capacity depends sensitively on temperature. For example, under a $6.1-\mathrm{mb} \mathrm{CO}_{2}$ at- mosphere, nontronite, an Fe-rich montmorillonite, can adsorb $11 \mathrm{~cm}^{3}$ (STP) $\mathrm{CO}_{2} / \mathrm{g}$ at $158^{\circ} \mathrm{K}$ but only $3.5 \mathrm{~cm}^{3}$ at $196^{\circ} \mathrm{K}$. Adsorption on fine-grained basalt has a similar temperature dependence, but the adsorptive capacity is about a factor of 10 less.

The dependence of adsorption on temperature must result in exchange of $\mathrm{CO}_{2}$ between the atmosphere and the surface. As surface temperatures fall, atmospheric $\mathrm{CO}_{2}$ will tend to be adsorbed into the surface materials; as temperatures rise, $\mathrm{CO}_{2}$ will tend to be driven off. The depth affected will depend on the time scale of the temperature changes. Diurnal temperature fluctuations affect only the top few centimeters; annual changes approximately the top meter. The exact values depend on the thermal conductivities and heat capacities of the materials involved (Fanale and Cannon, 1974). Long-term climatic changes can penetrate to much greater depths. Fanale and Cannon estimate that changes in the mean annual temperature due to precession, and changes in obliquity and eccentricity, which have times scales of $5 \times 10^{4}$ to $10^{6}$ years, should penetrate to depths of a few hundred meters to $1 \mathrm{~km}$. The effects on adsorption should, however, be greatest close to the surface where the temperature fluctuations are largest and the near-surface materials have the smallest grain size and the largest fraction of weathered products.

Fanale and Cannon (1979) modeled the effects of long-term climate changes on the adsorption and desorption of $\mathrm{CO}_{2}$ on the basis of a mean regolith thickness of $150 \mathrm{~m}$, using the term regolith simply to mean finegrained debris. They suggested that the regolith could be thought of in terms of three zones: a polar zone with a mean annual temperature of $158^{\circ} \mathrm{K}$, an intermediate latitude zone at $196^{\circ} \mathrm{K}$, and an equatorial zone at $233^{\circ} \mathrm{K}$. They assume on geologic grounds that the regolith is thicker at the poles than in the equatorial regions. A regolith of pure nontronite, they calculate, would contain $390 \mathrm{~g} \mathrm{CO}_{2} / \mathrm{cm}^{2}$ of the Martian surface, or 
the equivalent of an atmospheric pressure of $144 \mathrm{mb}$. This is probably an upper limit, for an average of $150 \mathrm{~m}$ of montmorillonitic clay over the whole planet is unlikely. More probably, there is a transition from highly adsorbing, dominantly clay materials at the surface to a less adsorbing megaregolith of less altered rock fragments at greater depths. Nevertheless, it is clear that the regolith has the potential for adsorbing many times the amount of $\mathrm{CO}_{2}$ than is currently in the atmosphere. Some $\mathrm{CO}_{2}$ is also condensed in the remnant south polar cap, but the cap covers only $0.01 \%$ of the planet's surface, and, even if very thick, would constitute only a fraction of the adsorbed inventory.

Mars is currently close to the middle of its obliquity range. At maximum obliquity, temperatures at the poles would be about $15^{\circ}$ higher than at present; equatorial temperatures would be a few degrees lower. Conversely, at minimum obliquity, polar temperatures would be $15^{\circ}$ lower than at present and equatorial temperatures slightly warmer (Ward, 1974). Fanale and Cannon (1979) showed that for their nontronite model, these temperature fluctuations result in an atmospheric pressure that varies between 0.5 and $22 \mathrm{mb}$. A regolith of fine-grained basalt would result in smaller variations.

The top $150 \mathrm{~m}$ or so of the surface may thus be subject to a slow flushing action by $\mathrm{CO}_{2}$ on a cycle of approximately $10^{5}$ years. The slow interchange may in part explain why the oxygen in the atmosphere shows little enrichment in ${ }^{18} \mathrm{O}$, as anticipated by exospheric exchange rates. The enrichment has been diluted by the large surface reservoir. Although interchange of oxygen with the atmosphere is achieved largely by movement of $\mathrm{CO}_{2}$, a large fraction of the oxygen in the surface may be combined as water, which is not as mobile. Fanale and Cannon suggest, therefore, that the $\mathrm{CO}_{2}$ may act as a carrier for oxygen and cause all the oxygen that is combined within the regolith to maintain isotopic identity with the atmosphere.

The flushing action may also affect the stability of water in materials close to the surface, by facilitating migration of water and establishment of thermodynamic equilibrium with the atmosphere. Under present climatic conditions, at latitudes below $40^{\circ}$, water and water-ice are unstable with respect to the present atmosphere at all depths (Farmer and Doms, 1979). If ice is present in the permafrost zone, which extends to depths of $1-2 \mathrm{~km}$ at these latitudes (Fanale, 1976), then it must be diffusively isolated from the atmosphere. Isolation may be effected by the regolith. Smoluchowski (1968) demonstrated that under stable climatic conditions, a relatively thin $(1 \mathrm{~m})$, fine-grained regolith could act as an effective diffusion barrier even on time scales of billions of years, and so claimed that ice could exist at relatively shallow depths, even in equatorial regions. Climate changes, causing adsorption and desorption of $\mathrm{CO}_{2}$ and forced migration of $\mathrm{CO}_{2}$ through the regolith, will, however, undermine the efficacy of the regolith as a diffusive barrier. Climate changes will tend, therefore, to eliminate ice in the upper parts of the permafrost zone in the equatorial latitudes.

\section{SUMMARY}

The layered terrain at the poles preserves a record of cyclic sedimentation that is probably caused by periodic changes in global climates. The topography of the surface of the deposits also has cyclic elements that could be related to the same climatic changes. Dust may currently be accumulating at the north pole because of condensation of the seasonal cap during global dust storms, but the site of accumulation will alternate from pole to pole with the 51,000 year precessional cycle. Longer-term cyclic variations in erosion and deposition may be caused by variations in eccentricity 
and obliquity. Variations in the orbital and rotational motions may also result in interchange of volatiles between the atmosphere and the near-surface materials, thereby causing periodic variations in atmospheric pressure, which have further climatic effects. Most of the evidence for climate change concerns the recent geologic past but a fragmentary record also exists of ancient periodic changes.

\section{REFERENCES}

Arvidson, R. E., A. Carusi, M. Coradini, M. Fulchignoni, C. Federico, R. Funicello, and M. SALAMONE (1976). Latitudinal variations of wind erosion of crater ejecta deposits on Mars. Icarus 27, 503-516.

CARR, M. H. (1979). Formation of Martian flood features by release of water from confined aquifers. $J$. Geophys. Res. 84, 2995-3007.

CARR, M. H. (1981). The Surface of Mars. Yale Univ. Press, New Haven, Conn.

Carr, M. H., and G. G. Schaber (1977). Martian permafrost features. J. Geophys. Res. 82, 40394065.

Cutts, J. A. (1973). Wind erosion in the Martian polar regions. J. Geophys. Res. 78, 4211-4221.

CutTs, J. A. (1980). Simulation of Stratigraphy of Martian Polar Layered Deposits. NASA Tech. Memo. 81776, pp. 63-65.

Cutts, J. A., K. R. Blasius, and W. J. Roberts (1979). Evolution of Martian polar landscape: Interplay of long term variation in perennial ice cover and dust storm activity. J. Geophys, Res. 84, 29752994.

Cutts, J. A., K. R. Blasius, G. A. Briggs, M. H. Carr, R. Greeley, and H. Masursky (1976). North polar region of Mars: Imaging results from Viking 2. Science 194, 1329-1337.

Dzurisin, D., AND K. R. Blasius (1975). Topography of the polar layered deposits of Mars. J. Geophys. Res. 82, 4225-4248.

Fanale, F. P. (1976). Martian volatiles: Their degassing history and geochemical fate. Icarus 28, 179 202.

Fanale, F. P., And W. A. Cannon (1974). Exchange of adsorbed $\mathrm{H}_{2} \mathrm{O}$ and $\mathrm{CO}_{2}$ between regolith and atmosphere of Mars caused by changes in surface insolation. J. Geophys. Res. 79, 3397-3402.

Fanale, F. P., and W. A. Cannon (1979). Mars: $\mathrm{CO}_{2}$ adsorption and capillary condensation on clays-Significance for volatile storage and atmosphere history. J. Geophys. Res. 84, 8404-8414.

FARMER, C. B., AND P. E. DOMS (1979). Global sea- sonal variation of water vapor on Mars and the implications for permafrost. J. Geophys. Res. 84, 2881-2888.

Farmer, C. B., D. W. Davies, and D. D. La Porte (1976). Mars: Northern summer ice cap-Water vapor observations from Viking 2. Science 194, 1339 1341.

Guest, J. E., P. S. Butterworth, ANd R. Greeley (1977). Geologic observations in the Cydonia region of Mars from Viking 1.J. Geophys. Res. 82, 41114120 .

HowarD, A. D. (1978). Origin of the stepped topography of the Martian poles. Icarus 34, 581-599.

HowARD, A. D. (1981). Etched Plains and Braided Ridges of the South Polar Region of Mars: Features Produced by Basal Melting of Ground Ice? NASA TM 84211, 286-288.

Kieffer, H. H., AND F. D. Palluconi (1979). The Climate of the Martian Polar Cap. NASA Conf. Publ. 2072, pp. 45-46.

Kieffer, H. H., S. C. Chase, T. Z. Martin, E. D. Miner, And F. D. Palluconi (1976). Martian north pole summer temperature: Dirty water ice. Science 194, 1341-1344.

Latham, G. V., M. Ewing, F. Press, G. Sutton, J. Dorman, Y. Nakamura, N. Toksoz, F. DuenNEBeIr, AND D. LAMMLEIN (1971). Passive Seismic Experiment. NASA SP-272, pp. 133-161.

LucChITTA, B. K. (1981). Mars and Earth: Comparison of cold-climate features. Icarus 45, 264-303.

MCElRoY, M. B., T. Y. Kong, and Y. L. Yung (1977). Photochemistry and evolution of Mars 'atmosphere: A Viking perspective.J. Geophys. Res. 82, 4379-4388.

Murray, B. C., W. R. Ward, and S. C. Young, (1973). Periodic insolation variations on Mars. $S$ c $i$ ence 180, 638-640.

Murray, B. C., L. A. Soderblom, J, A. Cutts, R. P. Sharp, D. J. Milton, and R. B. Leighton (1972). Geologic framework of the south polar region of Mars. Ic arus 17, 328-345.

Pollack, J. B., AND D. C. Black (1979). Implications of the gas compositional measurements of Pioneer Venus for the origin of planetary atmospheres. Science 205, 56-59.

Pollack, J. B., D. S. Colburn, M. Flaser, R Kahn, C. E. Carlston, And D. Pidek (1979). Properties and effects of dust particles suspended in the Martian atmosphere. J. Geophys. Res. 84, 2929 2945.

SharP, R. P. (1973). Mars: South polar pitted and etched terrain. J. Geophy's. Res. 78, 4222-4230.

ShaRP, R. P. (1974). Ice on Mars. J. Glaciol. 13, 173 185.

Smoluchowski, R. (1968). Mars: Retention of ice. Science 159, 1343-1350.

Soderblom, L. A., T. J, Kriedler, AND H. MASURSKY (1973). Latitudinal distribution of debris 
mantles on the Martian surface. J. Geophys. Res. 78, 4117-4122.

Toon, O. B., J. B. Pollack, W. Ward, J. A. Burns, AND K. BILSKI (1980). The astronomical theory of climate change on Mars. Icarus 44, 552-607.

Toulmin, P., A. K. Baird, B. C. Clark, K. Keil, H. J. Rose, R. P. Christian, P. H. Evans, and W.

C. Kelliher (1977). Geochemical and mineralogi- cal interpretation of the Viking inorganic chemical results. J. Geophys. Res. 82, 4625-4634.

WARD, W. R. (1974). Climatic variations on Mars, 1. Astronomic theory of insolation. I. Geophys. Res. 79, 3375-3386.

WARD, W. R., J. A. Burns, AND O. B. TOON (1979). Past obliquity oscillations of Mars: The role of the Tharsis uplift. J. Geophy's. Res. 84, 243-259. 